\title{
Exploring the Challenges Faced by Working Mothers and the Perceived Factors to Retain them in the Private Education Sector
}

\author{
Hasani De Ravindranath \\ Asia Pacific University of Technology and Innovation, 57000 Kuala Lumpur \\ Jugindar Singh Kartar Singh \\ Asia Pacific University of Technology and Innovation, 57000 Kuala Lumpur
}

Thilageswary Arumugam

Asia Pacific University of Technology and Innovation, 57000 Kuala Lumpur

Janitha Kularajasingam

Asia Pacific University of Technology and Innovation, 57000 Kuala Lumpur

Received: Feb. 7, $2021 \quad$ Accepted: Feb. 28, 2021 Online published: Feb. 25, 2021

doi:10.5296/ijhrs.v11i2.18457

URL: https://doi.org/10.5296/ijhrs.v11i2.18457

\begin{abstract}
The purpose of this exploratory study was to explore the challenges faced by working mothers in the education sector and the perceived policies and strategies to retain them in their current jobs. This basic qualitative study used in-depth semi-structured interviews to collect information from five working mothers with at least one child. Thematic analysis was done to analyse the data manually. The key challenges highlighted include work-life conflict, stereotyping, exhaustion, changing work schedule and career growth opportunities. The working mothers also stated that the key perceived policies and strategies to retain them include child-care support, working from home and flexible work arrangements. Generally, they stated that motherhood was their key priority, and they prioritised family overwork. The study provided an understanding to organisations on the challenges faced by working mothers
\end{abstract}


and what policies organisations should focus on to retain them. This study was the first of its kind, and it provided in-depth experience and views of working mothers in the education sector. This paper makes contributions to work-life integration and career theory.

Keywords: working mother, gender divide, work-life, retention

\section{Introduction}

Women participation in the workforce has increased, and this has been accompanied by more significant challenges they face in balancing and managing their role between work and family responsibilities (Marcinkus and Hamilton, 2006). Women make up $39.1 \%$ of the female labour force participation in Malaysia, out of which $62 \%$ are estimated to be mothers. Women constitute a significant percentage of the labour force, with approximately 6 million female participants, with a rise of 49,000 females joining the labour force in the second quarter of 2019. This translates to the female participation rate increasing higher than male participation, which only increased by 23,000 male participants in the second quarter of 2019 . Comparatively, the female labour force participation rate rose from 55.1\% in 2018 to $55.7 \%$ in 2019. In addition, $73 \%$ of women participating in the Malaysian labour force are in the prime fertility age bracket of 25-35 years of age (Malaysian Department of Statistics, 2019). However, women face several challenges and based on a survey, around $75 \%$ of Malaysian mothers quit their jobs due to a lack of flexibility (HrAsia, 2018). Another $94 \%$ of women surveyed said they would be looking for a new job in the next 12 months. A recent report by McKinsey (2020) reported that more than one in four women are contemplating either resigning from their workplace or downsizing their careers. This points towards the severe problems related to the retention of women in the workforce.

According to gender ratio reports by Ritchie and Roser (2019), women comprise $49 \%$ of the global population. This statistic is very significant because as the female labour force participation rate is increasing, women are viewed as a valuable asset to the labour force in regard to gender diversity, competency, and productivity to organisations (Turban, $\mathrm{Wu}$, and Zhang, 2019). Unfortunately, it was reported that the retention of women in the Malaysian workforce is challenging for Malaysian employers due to the lack of gender diversity initiatives and inclusion programmes to attract and retain women who are planning motherhood and who are currently mothers (TalentCorp, 2013). The Malaysian workplace is believed by many to be patriarchal and male-dominated due to the lack of practising theories of equal opportunities. Survey results by Talent Corp (2013) also state that women are predominantly marginalised due to the belief of them prioritising family over their work. Malaysia's male-dominated work environment is reportedly a contributor to women leaving their careers as they lack social acceptance when occupying leadership roles due to the adverse effects it can have on their familial responsibilities (TalentCorp,2013).

Past studies have identified several reasons why women quit their jobs. The survey by HRAsia (2018) found that the key reason why women quit their jobs encompasses lack of flexibility (75\%), concerns about child-care (60\%) and unsupportive bosses and work environment (55\%). Another challenge is gender biasness. A survey by Williams, Phillips and Hall (2016) found that $64 \%$ of gender bias was triggered by motherhood. In the study by 
Williams, Phillips and Hall (2016), around 55.3\% of women reported situations in which gender bias was the cause of conflicts among women. Adhikari (2012) further stated that women's problems include stress, exhaustion, and anxiety. This may be due to their challenge to balance their role at the workplace and concern for the family and children. Past studies also showed that ill-health among women would adversely affect employment opportunities (Austen and Ong, 2010). As Yapp (2018) stated, the bulk of household work is women's responsibility despite most of them now going to work in organisations. Yapp (2018) highlighted that women spent three times longer on household chores than men. The stress that working mothers encounter in achieving work-life balance can lead to lower performance (Sudha and Karthikeyan, 2014).

There are also some policies and practices that women perceive will deter them from quitting their jobs. McKinsey (2020) reported that "broken rung" continues to be a significant barrier faced by women. The survey by HRAsia (2018) found some of the policies and practices to overcome the hurdles they are encountering encompass flexible work arrangements $(46 \%)$ and a transition period when returning to work (20\%). Austen and Ong (2013) pointed out that there is a relationship between reduced working hours and intention to leave. Another study by Nie, Lämsä, and Pučètaitè (2018) pointed out that organisational policies which support work-family integration can lead to lower turnover intentions by female employees. Jabeen, Friesen, and Ghoudi (2018) examined the quality of work life. The study found a positive impact on the quality of work-life on the turnover intention of women. The study among respondents in the education sector by Hundera (2014) revealed that the levels of role stress and intention to leave is higher among female academic staff.

The education sector in Malaysia has more women employees than males. There was a total of 423, 466 teachers enrolled in 2018, and 298, 237 of them were females (Ministry of Education, 2018). Despite the education industry being one of the top females dominating industries globally, most leadership positions are still held by men. Evidence indicates that working mothers are facing challenges and planning to leave the workforce. In terms of career progression, there is a lack of women in senior positions. This means that women are under-represented across (Morley, Berma, and Hamid, 2017). The evidence from past literature shows that retention of women is a critical issue. There is an overwhelming need for employers to start looking at the challenges women face and the perceived factors that can influence their retention. However, there is a dearth of research and literature relating to the challenges and policies to retain working mothers in the education sector in Kuala Lumpur. In addition, past studies were mostly causal studies that looked at the cause-and-effect relationships. There is a paucity of research that has explored working mothers experience of challenges, and the factors they perceive will motivate them to stay using qualitative methods. Recognising the importance of working mothers, this study, then, offers an exploratory perspective of the challenges faced by working mothers and the perceived factors that can influence their retention. This study will provide in-depth knowledge of the challenges and the perceived factors that will spur working mothers to stay in the workforce. This information and insights provide a better understanding of this phenomenon, and business organisations can implement policies and practices to support working mothers' retention. 
This study was focused on answering the following research questions.

Research Question 1: What are the challenges faced by working mothers in the private education industry of Kuala Lumpur?

Research Question 2: What are the perceived organisational policies and practices that can influence working mothers to continue their employment?

\section{Literature Review}

\section{Challenges and problems faced by working mothers.}

Working mothers face several challenges regarding juggling their roles related to the household and as an employee. It was reported by McKinsey (2020) that women continuously face discrimination in the workplace, and for every 100 men promoted to manager, only 85 women were promoted. One of the main challenge or problem highlighted was discrimination against women in the workplace. The issue of discrimination against women in the workplace is highlighted in several studies, and it continues to be an impediment to gender equality in the workplace (Sultana and Zulkefli, 2012; Gorman, 2005). Scholars and researchers generally have related discrimination against women in the workplace to cultural beliefs, socioeconomic norms and values (Ridgeway and England 2007; Sultana and Zulkefli, 2012). According to a survey by Bright Horizons (2018), several working mothers stated that doing more or putting in the effort at work may not always lead to growth in their careers. They admitted that there are obstacles along the path in their career growth. The survey revealed that $82 \%$ of working mothers encountered barriers that prevented them from becoming leaders. In a survey carried out by the Women's Aid Organisation (2016) that polled a total of 222 women in Malaysia, around $40 \%$ of women stated that they had experienced job discrimination due to their pregnancy. The WAO survey revealed that the five ways in which pregnant women were discriminated against encompass low promotion opportunities, making their jobs redundant, demotion, placing them on prolonged probation, and in extreme cases terminating their jobs.

Past researchers and scholars have also indicated that gender stereotyping may contribute to discrimination against women in the workplace (Bobbitt-Zeher, 2011). Bobbitt-Zeher (2011) explained that women are stereotyped as less invested workers, viewed as sexual objects, and there are notions of women's traits as incompatible with specific jobs. Stereotyping can be segregated as descriptive and prescriptive stereotyping. Burgess and Borgida's (1999) stated that descriptive stereotyping normally occurs in traditionally male-dominated settings. However, in female-dominated settings, both descriptive and prescriptive stereotyping occurs. Gender stereotyping will compromise working mothers' capabilities in terms of competency, flexibility, and commitment to the workplace. Social psychological theories propose that prevalent stereotypes against working mothers make them ultimately question their performance capacity and dedication to their careers (Greer and Morgan, 2016).

In a study by Kremer (2016), women reported more significant work-family conflict and family-work conflict than men. This leads to stress, burnout, anxiety, ill-health, and other challenges faced by working mothers. Despite going to work, a large portion of the family 
role and the related household work is still the responsibility of women (Yapp, 2018). Women spent three times longer time doing household chores compared to men (Yapp, 2018). Many working mothers believe they can fulfil all their responsibilities, but at the expense of exhaustion (Rendon, 2016). This conflict between work and family arises because women role is time-consuming and stressful (Schueller-Weidekamm, and Kautzky-Willer, 2012). Studies have shown that women encounter higher work-family conflict levels and greater stress and burnout compared to men (Hill et al., 2008). The stress arising out of handling work and family commitments can lead to negative consequences. The stress that working mothers encounter in their role to achieve work-life balance can lead to burnout and lower performance (Sudha \& Karthikeyan, 2014; Schueller-Weidekamm and Kautzky-Willer, 2012). Schueller-Weidekamm and Kautzky-Willer (2012) explained that the conflict between work and family leads to stress and burnout. This further affects the working mother's family and work roles. The conflict theory can explain the conflict. According to this theory, success or satisfaction in one environment relates to loss or sacrifice in the other environment. The two environments have different norms and requirements (Evans and Bartolome, 1984). The conflict between work-related demands and family roles demands work-life balance and flexibility by working mothers (Tajlili, 2014).

Many working mothers believe they can fulfil all their responsibilities, but at the expense of stress and exhaustion (Rendon, 2016). The exhaustion can be the result of job spillover. A study by Grice et al. (2011) revealed that working mothers with high levels of job spill over to home had mental health-related problems. It was reported in The Guardian newspaper that eighteen per cent of working mothers are more stressed than other people (Ramasamy, 2019). In addition, mothers working full-time and have two or more children are $40 \%$ more stressed than others. In another study, Sundaresan (2014) also reported that $67 \%$ of working mothers who participated in the research stated that they suffer from excessive work burden. They experienced challenges with their children's tasks, careers, and social circle. In addition, the imbalance of work and family life also leaves working mothers exhausted and with little time to take care of themselves. In the study, the majority of the respondents agreed that they experience high levels of stress and anxiety, which even prevented some of them from aspiring to progress in their careers as exhaustion from poor work-life balance inhibits working mothers from realising their full potential (Sundaresan, 2014). Furthermore, organisations' adverse effects arising from exhausted working mothers include absenteeism, tardiness, demoralisation, lower job satisfaction, and low productivity.

Another challenge or problem faced is the career growth opportunities for women compared to men. Evidence from past studies suggests that working mothers' face several barriers in their career advancement (Kuruppuarachchi, and Surangi, 2020; Islam and Jantan, 2017). Kuruppuarachchi and Surangi (2020) stated that the "glass ceiling" effect is one of the barriers experienced by women in their career advancement. There are other individual barriers, such as low self-confidence and low-risk taking (Worrall et al., 2010; Kuruppuarachchi and Surangi, 2020). There are also organisational practices that are related to organisational culture and structure (Tlaiss and Kauser, 2010). Most organisations are nowadays male-oriented, and not much support and care are focused on women needs and 
requirements (Ismail and Ibrahim, 2008). Studies have also shown a gap in the relationship between motherhood and women's career advancement (Brown (2010). This can be attributed to several factors. One factor is the societal judgement placed on working mothers' commitment levels (Brown, 2010). It is generally believed in several cultures that men can commit more time to work than women, and women agree to this belief as they have more household demands to fulfil. Based on the social role theory, King (2008) argued that it is theorised that stereotypes concerning working mothers will drive biased perceptions about their attitudes toward family and job commitments. This will account for the existence of the 'maternal wall'. Thus, organisations are believed to practice maternal bias by demonstrating gender differences in perceptions of work-family attitudes that influence career advancement (King, 2008). However, in contrast, it was argued by Sandberg (2013) that the reason why women are underrepresented in positions of power and given lower career development opportunities is voluntary and purely backed up by personal preference of women and comfort in their existing career positions.

Past studies have revealed that women in the academic sector spent more time participating in the deliverance of education than on research compared to their male faculty members. This resulted in women and men in academia being treated differently in the work environment. Women perceived that their work quality is scrutinised and valued less due to the constraints placed on women because of familial responsibilities (Bingham and Nix, 2010). Past studies also showed that academicians are among professions that have the highest levels of job stress (Stoeber and Rennert, 2008). Therefore, it can be concluded that women in the academic field are more likely to experience higher exhaustion levels and stress, which is frequently conceptualised as a central dimension of burnout (Stoeber and Rennert, 2008).

\section{Policies and practices to retain working mothers.}

Scholars and researchers have stressed flexibility and flexible work arrangements as one of the solutions to retain working mothers. In research carried out by Rakin (2018), 46\% of the participants agreed that flexible work arrangements would make them consider continuing in the workforce. A survey done by Talent Corp (2013) stated that flexible work arrangements were key to retaining women at the workplace as it allows them to integrate their motherhood and professional responsibilities better. Flexible working opportunities can also motivate working mothers to take up more career advancement opportunities if they are provided with the necessary support to manage their time effectively. Furthermore, flexibility related policies are also seen as easing the transition of re-entering the workplace after maternity leave. Flexibility is a significant aspect in enabling women to balance their work and family lives as flexibility, along with autonomy, can benefit individuals and increase their competency levels (Kelly and Marin, 1998). Furthermore, since working mothers have domestic responsibilities to uphold, flexibility is crucial for them to maintain adequate work/family balance levels. Previous studies have found work/family conflict associated with poor parental preferences, which leads to lifestyle preferences that contribute to inadequate work/family balance. As a result, social policymakers are challenged when addressing the complexity of work/family balance while giving equal consideration to economic productivity (Losconcz and Bortolotto, 2009). 
Another solution to the retention of women is the provision of child-care support. According to Talent Corp (2013), reliable and accessible child-care is of significant importance for working mothers in the pursuit of continuing their professional lives. Studies have shown that working mothers experience childcare-related challenges (Moilanen et al., 2016). Hein and Cassirer (2010) also stated that working mothers' problems are finding appropriate child-care for their children while they work. Therefore, employers' child-care support can help mitigate the likelihood of mothers having to stay home to care for their children. The affordability of high-quality child-care is an ongoing issue amongst working mothers in Malaysia. Therefore, organisations enforcing policies in-support of child-care may possibly improve the retention rates of females in the workforce. Child-care assistance may be critical for families struggling with finances, resulting in working mothers relying on informal child-care arrangements, which can be a source of added stress (Boushey and Wright, 2004). However, in Malaysia, only $7 \%$ of the nation's employers have child-care support policies and which can explain why $35 \%$ of working mothers leaving the workforce is due to child-care being too expensive (TalentCorp, 2013). Employers should also have breastfeeding support policies and practices that fit their company's budget and resources (Dinour, and Szaro, 2017).

Support for diversity and inclusion in the workplace policies is another potential predictor of retention of working mothers. Encouraging gender diversity in the workplace is crucial for the retention of women. As stated in the report by McKinsey (2020), companies can close gender gaps by fostering diversity and providing equal opportunities. Past studies have revealed a relationship between employees' diversity and turnover (Leonard and Levine, 2006). Leonard and Levine (2006) studied the effect of gender diversity on turnover rates among sales employees and found evidence linking workplace gender diversity and higher quit rates among women employees. Similarly, another study by Giuliano et al. (2006) found evidence between gender differences and quit rates. Gender diversity improves a company's potential and the economic standings of those companies when diversity inclusion policies are adopted (Raley, 2019).

Several studies have shown gender equality in the workplace strengthens the capabilities, and when policies are mandated, it also helps the country's economic status. Gender equality in the workplace is expected to strengthen the practice of the fair and impartial distribution of opportunities and resources for both men and women. However, in the current workplace, role limits have resulted in divisive identities between men and women (Sharma and Sharma, 2012). A study by Elwér, et al. (2013) revealed that patterns of gender equality at the workplace were related to psychological distress among women only. This means that gender inequality in the workplace led to situations where women were disadvantaged. Elwér et al. (2013) revealed that gender equality at the workplace was related to women's mental health. A study by $\mathrm{Wu}$ and Cheng (2016) further highlighted that gender equality policy also promotes an organisation's growth. However, in many countries, the "glass ceiling" concept inhibits women from being given equal workplace opportunities. This rallies back to the gender stereotypes, which can act as an obstacle that can be quite complex to diminish if the top management does not exhibit the relevant efforts. Emphasis must be placed on the talent pool acquired by human resource departments in Malaysia in order to influence corporate 
behaviour (TalentCorp, 2013). It was also found that organisations lose up to $50 \%$ of their consumer markets by side-lining women. Therefore, looking out for women's needs in the workplace is essential for organisations to thrive to their highest potential (TalentCorp, 2013).

\section{Methodology}

This was an exploratory study to determine the challenges faced by working mothers in the academia sector and to gather insight into their perceived strategies to help retain working mothers in the workforce. The study upheld the interpretivism philosophy. This philosophy asserts that an intervention's subjective interpretation is essential for a particular reality to be understood. Therefore, the adoption of the phenomenology strategy is paramount to the interpretivism philosophy. It helps to identify the essence of lived human experiences about a phenomenon as expressed by participants (Saunders et al., 2016). An inductive approach was used in this study as it was necessary to gauge the participants' feelings to understand better the nature of the problem (Saunders et al., 2016). With the guidance of the phenomenological research paradigm, the use of a qualitative research method to collect primary data through interviews and open-ended questionnaires allowed the researcher to gain a deeper understanding by taking into account the different voices and perspectives of the study population. The time horizon used was cross-sectional as it paves the way for further study.

The target population of this study were working mothers in Private Universities in Kuala Lumpur. Purposive sampling was more appropriate for this study because a clear inclusion criterion was set, and only cases that met the criteria were selected for the interview (Saunders et al., 2016). The sample size was in line with the requirement to continue data collection until the saturation point is reached (Merriam and Tisdell, 2018). In this study, where the participants are homogeneous, the recommended target sample size was 4-12 participants (Saunders et al. 2016). For this study, there were five respondents from a homogeneous background.

This study used an inductive approach, and semi-structured interviews were more appropriate to collect non-numerical data (Merriam and Tisdell, 2016). The semi-structured interview strategy allowed deeper probing and collection of in-depth data that provided a deep understanding of the phenomena. Due to Covid-19 restrictions, most of the interviews were done online through tools like Zoom and Google Meet. Permission was obtained to record the interview from the participant. Open-ended questions were asked, followed by probing questions. Ethical principles of privacy and confidentiality were fully complied with by the researcher. Transcription of the recordings was done to facilitate the data analysis.

This study applied the "manual thematic coding analysis" strategy to generalise the findings. Thematic analysis was chosen because it provides flexibility to analyse the data leading to rich descriptions, explanations, and theorising. The purpose of thematic analysis was to search for themes or patterns in the collected data (Saunders et al., 2016). In the thematic analysis, coding was done. In this inductive approach, coding was guided by the purpose of the research and the research questions (Saunders et al., 2016). The objective was to categorise the codes and identify the themes or patterns. The procedure includes comprehension and analysis of the data, coding, categorising, and identifying the patterns and 
themes and writing the report. After the coding was completed, the search for themes started. At this point, the analysis was to search for patterns and relationships in the codes to create themes that were related to the research questions (Saunders et al., 2016).

To check the data's trustworthiness, the four criteria stated by Lincoln and Guba (1985) were referred. The four criteria specified for trustworthiness by Lincoln and Guba (1985) include credibility, transferability, dependability, and confirmability. Credibility refers to the focus of the research. It is confidence how clearly the data address the intended focus (Polit \& Beck, 2012). In this study, credibility was addressed through member checking. In this study, much focus was placed on member validation. The participants were given the transcript of the raw data to confirm. They were requested to check, and comment and all comments and changes were recorded (Saunders et al., 2016). The stability of data over time and under different conditions is referred to as dependability. To address the dependability of data, all records and changes were saved and maintained. An audit trail was strictly complied with by the researcher (Koch, 1994). Markers that include reasons for analytical or methodological choices were used to ensure that readers can understand why and how decisions were provided to meet the criterion of confirmability (Koch, 1994).

\section{Results and discussions}

There were five participants in this study. All five participants were full time working mothers. They were all Malaysian lecturers in Private Universities in Malaysia. All were married with at least one child. The participants were, therefore, considered homogeneous. To maintain the ethical principle of privacy and confidentiality, the names were kept confidential. They were referred to as Respondent 1, 2, 3, 4 and 5.

\section{Research Question 1}

The first research question aimed to get insights into the challenges faced by working mothers based on their lived experiences. Based on the thematic analysis, the main themes that emerged encompass work-life conflict, excessive work and exhaustion, interference caused by changes in work schedules, stereotyping, and career growth.

\section{Work-life conflict}

Most of the participants stated that the work-life conflict was the main challenge that they encountered. Most of the academic jobs require substantial time to be devoted to work that involves lecturing and handling other student-related matters. This job requires a substantial amount of time to be spent on work-related responsibilities, and working mothers find it very difficult because of family commitments. They generally found it difficult to cope with the pressures related to work responsibilities and the demands related to family responsibilities. The following comments are indicative of the view and expressed by the participants:

Participant 2: "My role as a mother and lecturer is very challenging because I have to take care of my children and fulfil my work-related responsibilities. I have a 5-year-old child, and I need to help with her studies and homework. I have a baby too, and I am still breastfeeding him. I also need to do many household chores. 
Participant 4: "Career development is important but allocating time to work and family responsibilities is a challenge. To cope with family responsibilities and my children and, at the same time, being efficient at work requires a lot of time and energy. I also feel that it is not fair to neglect anyone of my responsibilities".

Participant 5: "Managing time between workload and family expectations is still an ongoing challenge. There is also a lot of work that spill over into my home."

The participants generally expressed their difficulties in balancing their work-related and family responsibilities. In addition to their work-related responsibilities, women also carry the burden of handling family matters, caring for children and doing household tasks. This leads to stress due to job spill into their home and family role. They need to make sacrifices due to conflict in the work and home environment. Past studies have also highlighted similar concerns (Schueller-Weidekamm, and Kautzky-Willer, 2012; Hill et al., 2008; Kremer, 2016). Schueller-Weidekamm and Kautzky-Willer (2012) highlighted that the conflict between work and family arises because women's role is time-consuming and stressful. Women encounter higher work-family conflict levels and greater stress and burnout than men (Hill et al., 2008). Women also experience higher challenges than males in balancing their work and family commitments (Sundaresan, 2015).

\section{Excessive work and exhaustion}

An extension of work-life conflict was excessive work and exhaustion. All participants described themselves as being exhausted, experience frequent tiredness, and had limited or no time to take care of their individual well-being. They expressed that handling work-related roles and family commitments result in a lot of anxiety and confusion on their priorities and what needs to be sacrificed. Some women choose to sacrifice their career due to their focus on family. All the participants, in one way or other, stated that they experienced high levels of exhaustion which can also be mirrored as symptoms of stress. This study's findings revealed that working mothers sacrifice their free time and have limited to no time to take focus and care for their own well-being. Time management was also mentioned as an obstacle to balancing their work and home environment effectively. The following comments are indicative of the views expressed by the participants.

Participant 4: "I often feel very tired and worn out at the end of the day. I hardly have time for myself. I am unable to take care of myself."

Participant 4: "I feel much anxiety about fulfilling my role and I and do not even have time to spend on my own self".

Participant 6: "A lot of time is spent on travelling. In addition, as an academician, I have to manage several work-related tasks. I also must handle most of the household matters. At the end of the day, I feel exhausted".

Participant 2: "I bring home a lot of work as there are several administrative tasks such as marking of papers that I need to handle within the deadlines. This gives me more stress".

It can be seen from this study that the workload of academicians is high, and they also need 
to handle their family and children. This exerts a lot of strain, and they find it very difficult to cope with the pressures of work and family commitments. This finding is consistent with past studies that revealed that a large portion of the family role and the related household work is still the responsibility of women (Yapp, 2018). Past studies have revealed that women spent three times longer time doing household chores than men (Yapp, 2018). Many working mothers believe they can fulfil all their responsibilities, but at the expense of exhaustion (Rendon, 2016). Exhaustion can lead to ill health among women, which can adversely affect the employment opportunities and advancement of women in their careers (Austen and Ong, 2010). In addition, as women take back a lot of their work, the constant high levels of job spill over to home can lead to mental health-related problems.

\section{Long work hours and changing work schedule.}

The work schedules of academicians are not fixed. The respondents stated that almost every week, there are changes to the academicians teaching schedules. This affects their ability to plan their time and adds to the uncertainties and anxieties that they encounter. They also perform other tasks during non-working hours, such as advising students and marking papers. In addition to their routine tasks and family responsibilities, these tasks increase their stress and affect their performance. This study demonstrated that a few participants felt guilty when they could not attend to their children's needs the way they would ideally have preferred to. The following comments are indicative of the view and expressed by the participants.

Participant 1: "The normal work routine worked perfectly well, and no issues were faced as long as sudden task additions and changes do not come up. The changes in the work schedule affect my ability to plan my activities".

Participant 2: "The regular work schedule itself was leading to an imbalance in supporting the role that I must give priority. I have a new-born baby, and as a working mother, it is quite challenging because I must take care of my children and work. As an educator, my work does not end at the University, and when I go back home, I still have a lot to do, like preparing for the next day's classes, and besides that, I have other paperwork to be done as well. If your children are a little older, it is much easier to handle compared to when they are much younger. Additionally, work schedule imbalance can potentially result in exhaustion and further reduce working mothers' capabilities".

Long working hours and uncertain working schedules can lead to negative outcomes. Long working hours by women can be associated with depression, weight gain, smoking and alcohol consumption. A study by Shields (1999) stated that women who worked long hours had increased odds of subsequently experiencing depression, smoking, and drinking alcohol. Long working hours also lead to a higher risk of stroke and cardiovascular disease than those working standard hours (Kivimäki et al., 2015). Long working long hours exacerbates the structural inequality of gender. In addition, women's career paths can be the dichotomised patterns of either emulating workplace masculinity or leaving their jobs (Nemoto, 2013).

\section{Stereotyping and growth in the workplace}

Workplace stereotyping against working mothers has been regarded as a contributor to slow 
growth opportunities. Interestingly, this study found that there were some contradictory views relating to stereotyping in the workplace. The following comments are indicative of the views expressed by the participants:

Participant 1: "If ten years ago, if you asked me this, then I would say yes, there is a bias, but nowadays there is no difference between male and female in terms of gaining knowledge, exposure, independence. Everything has become equal".

Participant 3: "I don't agree with stereotyping and biasness in the education industry when it comes to women in leadership roles and other career advancement opportunities. Both men and women are equal in the education industry. If you do well and perform well, then you do get what you deserve".

Participant 4: "In the education industry, the leadership roles are still dominated by men. This is due to the dual roles'women play both back at home and work, limiting their chances and opportunities to attain higher positions.

Participant 5: "I think men are more focused on career, but women must manage their career and family in a balanced manner. Hence females cannot give higher priority to their career, unlike men. Employers prefer men because they can make decisions about work as they are fully focused on work. People tend to think that working mothers care about family matters, especially when it concerns children's well-being".

The study generally pointed towards the assigned gender to various leadership traits, resulting in the tendency to perpetuate stereotypes. Gender plays a significant role in career growth and leadership positions within organisations. When working women become mothers, they must challenge the perceptions and stereotypes. Working mothers are perceived as not be able to devote attention to work because of family obligations. Therefore, it may be nearly impossible for a working mother to advance in her career. However, there were differences in views from the participants in this study, and this could be due to the normative acceptance by some working women. There can be the presence of cultural support, but the study revealed that strongly male-dominant cultures are prevalent. Professional success in some fields requires stereotypically masculine behaviour. However, working women are being penalised in work domains through different forms of gender harassment (Leskinen et al., 2015). This can lead to discrimination against women throughout their careers, from hiring to opportunities for career advancement.

\section{Research question 2}

The second research question aimed to understand perceived organisational policies or strategies that can be adapted to retain working mothers. Findings of the perceived organisational strategies to retain working mothers was a critical component of this study in order to identify organisational practices which support the work/family balance amongst working mothers according to their lived experiences as the female labour force participation rate is growing rapidly and women may have biological desires to start family planning. All the participants of this study discussed what support systems and organisational strategies they rely on to fulfil their work and familial responsibilities. Some organisational practices 
they perceive would help out working mothers immensely. Overwhelmingly, all participants acknowledged their reliance on grandparents and/or daycare as their support systems in order to achieve an effective balance between work and family, which was also used as grounds to base their perceived strategies.

\section{Child-care support}

This was a common theme amongst many participants. Child-care support in terms of having on-site daycare was greatly preferred as it would be an ideal strategy to help working mothers with their main challenge - work/family conflict. Some of the views expressed by the participants are as follows:

Participant 1: "I do not have anyone at home to depend on for help. It would be convenient to bring my children to the on-site daycare in case of any emergencies in the morning. This policy is lacking in the education industry. There is no policies and support for child-care or other personal matters affecting employees".

Participant 3: "For me, work is important, but children and family are also important. My employers need to understand my role".

To resolve the challenges currently faced by working mothers, this study found that working mothers need support from the organisation. The absence of this highly preferred strategy in the private education sector of Kuala Lumpur contributes to the fact of why $35 \%$ of working mothers in Malaysia leave the workforce due to limited child-care support. Past studies have also stated that working mothers' problems are finding appropriate child-care for their children while they work (Moilanen et al., 2016; Hein and Cassirer (2010). Therefore, adopting child-care support strategies can greatly act as a strong support system in assisting working mothers to fulfil their dual role responsibilities. This will further enable them to combat exhaustion, reduce absenteeism, increase productivity, and ultimately increase retention. This study provided evidence that child-care support without relying on grandparents would immensely work in favour of working mothers. Employers' child-care support can help mitigate the likelihood of mothers having to stay home to care for their children. Working mothers should be given the flexibility to take breaks during their working hours to care for their children.

\section{Flexible work arrangements}

Another perceived solution was flexible work arrangements. In this study, it was found that the majority of the participants preferred flexible work arrangements. Generally, the participants stated that there are no organisational strategies or policies to support flexible work arrangements. The views expressed are stated below:

Participant 3: "To enable me to pursue further studies and at the same time handle other tasks, flexibility would help me a lot. Completion of my studies will further benefit the organisation in term of University ranking. My main challenges as a working mother are to balance my studies, career, and family-related tasks.

Participant 5: "Flexible work arrangements will allow me to manage my work-related and 
family-related matters. However, the organisation has no formal policy on flexible work arrangement".

In this study, it was clear that flexibility would assist in career advancement opportunities and possibly achieve leadership roles in the education industry for this participant. Flexible working hours could increase working mothers' intention to stay and their career advancement opportunities. Flexible working hours could provide working mothers with the autonomy to control their work schedule. This can be of value for developing better work/family balance routines, which can lower the turnover rates of women in organisations. Furthermore, since three out of six participants stated that organisations had established no current strategies to support working mothers, it would be ideal for organisations, specifically those in the education industry, to consider looking into ways this strategy can be incorporated into working mothers' work schedules as this is a clear need which is currently not formally implemented.

\section{Work from home}

The majority of the participants expressed that one of the best organisational practices, which is perceived to be attractive to working mothers in the education industry, would be to offer remote working arrangements. This would significantly reduce the challenges they face. Some of the views expressed were as follows:

Participant 2: "I have a baby, and the policy to conduct my evening classes from home would be ideal for $m e^{\prime \prime}$.

Participant 5: "For me, the working from home option would be very useful. However, this may not be attractive to all working mothers".

Participant 1: "I feel that working from home stirred up emotions of guilt because I could not attend to my children although there were within arm's reach. There are challenges related to working from home, such as interruptions caused by children".

Work from home was another perceived solution to retain working mothers. Past studies also showed that women appreciated the opportunity to work from home more than men. This will enable them to ensure a healthier life. To be successful, women working from home must improve their communications skills, time management and ability to work independently (Raišienè et al., 2020). Although the women stated that working from home was one of the options, there were some disagreements related to the option to work from home. Parental involvement is absolutely needed for giving their children a loving and secure childhood. In addition, disturbances and interruptions are more likely to impact the dual role responsibilities as attention will have to be given to both work and family simultaneously. However, women with school-going children can effectively manage to work from home. Moreover, routine-based work helps working mothers thrive, and therefore the working from home option may be a solution to changing work schedules.

\section{Implications}

This study helped to understand the challenges faced by working mothers in the modern 
workplace as well as the perceived strategies that can retain them. This study revealed the key challenges and the impact those challenges had on the well-being of working mothers. This study also revealed the perceived strategies to help and retain working mothers in the workforce. This study found that working mothers in academia in Kuala Lumpur are overwhelmingly exhausted and face stress. This is a significant finding as it could potentially hinder females from joining the education industry in the future or continue working. Therefore, this study's findings can also contribute to the development of policies to support working mothers. Since the education industry is female dominated, this study's findings are crucial when creating employee policies for this specific industry as the private sector is usually competitive. Therefore, employees can easily switch to different organisations. In order to retain women and working mothers in the private sector of academia, policies for working mothers in private educational institutions must be attractive as part of their competitive corporate strategy, especially in today's competitive economy. This study's findings also have implications for working mothers as it provides them with a deeper understanding of the challenges and the perceived factors that can retain them in their current jobs. Working women must find ways to achieve a harmonious balance in work and family-related spheres of their lives. Furthermore, this study also contributes to the theory of a myriad of topics relating to working mothers in Malaysia, which was one of the gaps that prompted this particular study in this region. Government bodies and organisations can also view this study's findings as useful when introducing work-life balance policies in the future. Without governments' support, working mothers' effective work-life policies will not be pursued quickly and seriously enough.

\section{Limitations and future research}

This qualitative study collected information relating to working mothers' subjective experiences in the educational sector in Malaysia. Future studies should be expanded to other sectors, such as the public sector. This was only a qualitative study, and future studies should consider mixed-method studies such as an exploratory sequential study to obtain better information and validate the findings. The explanatory sequential study should also consider the collection of data from more than one source. The mixed method's quantitative phase can provide more in-depth information to integrate and support the findings during the study's quantitative phase. The diversity or differences due to age, position in the organisation, social status and family size were not included in this study. For instance, studies involving single mothers may provide a different viewpoint. Therefore, future studies should consider the demographics to get a greater diversity of voice about challenges encountered and the perceived solutions to retain working mothers.

\section{References}

Adhikari, D. (2012). Anxiety and Depression: Comparative Study between working and Non-Working mothers. Global Journal of Human Social Science Sociology, Economics \& Political Science, 12(12), 1-7.

Austen, S., \& Ong, R. (2010). The employment transitions of mid-life women: Health and care effects. Ageing \& Society, 30(2), 207-227 
Austen, S., \& Ong, R. (2013). The effects of ill health and informal care roles on the employment retention of mid-life women: does the workplace matter? Journal of Industrial Relations, 55(5), 663-680.

Bingham, T., \& Nix, S. J. (2010). Women Faculty in Higher Education: A Case Study on Gender Bias. In Forum on Public Policy Online (Vol. 2010, No. 2). Oxford Round Table. 406 West Florida Avenue, Urbana, IL 61801.

Bobbitt-Zeher, D. (2011). Gender discrimination at work: Connecting gender stereotypes, institutional policies, and gender composition of the workplace. Gender \& Society, 25(6), 764-786. https://doi.org/10.1177/0891243211424741

Boushey, H., \& Wright, J. (2004). Working Moms and Childcare. https://www.researchgate.net/publication/237553521_Working_Moms_and_Child_Ca

Bright Horizons (2018). Modern Family Index 2018. https://www.brighthorizons.com/-/media/bh-new/newsroom/media$\mathrm{kit} / \mathrm{mfi}$ _2018_report_final.ashx

Brown, L. (2010). The relationship between motherhood and professional advancement. Employee Relations, 32(5), 470-494. https://doi.org/10.1108/01425451011061649

Burgess, D., \& Borgida, E. (1999). Who women are who women should be: Descriptive and prescriptive gender stereotyping in sex discrimination. Psychology, Public Policy, and Law, $5(3), 665-692$

Dinour, L. M., \& Szaro, J. M. (2017). Employer-based programs to support breastfeeding among working mothers: a systematic review. Breastfeeding Medicine, 12(3), 131-141.

Elwér, S., Harryson, L., Bolin, M., \& Hammarström, A. (2013). Patterns of gender equality at workplaces and psychological distress. PloS one, 8(1), e53246. https://doi.org/10.1371/journal.pone.0053246

Evans, P., \& Bartolomé, F. (1984). The changing pictures of the relationship between careers and family. Journal of Organizational Behavior, 5(1), 9-21. https://doi.org/10.1002/job.4030050103

Gorman, E. H. (2005). Gender stereotypes, same-gender preferences, and organisational variation in the hiring of women: Evidence from law firms. American Sociological Review, $70(4), 702-28$.

Greer, T. W., \& Morgan, W. B. (2016). Employed mother stereotypes and linkages to work-family conflict and enrichment. In C. Spitzmueller \& R. A. Matthews (Eds.), Research perspectives on work and the transition to motherhood (p. 199-216). Springer International Publishing. https://doi.org/10.1007/978-3-319-41121-7_10

Grice, M. M., McGovern, P. M., Alexander, B. H., Ukestad, L., \& Hellerstedt, W. (2011).

Balancing work and family after childbirth: A longitudinal analysis. Women's Health Issues, 21(1), 19-27. https://doi.org/10.1016/j.whi.2010.08.003 


\section{Mll Macrothink}

International Journal of Human Resource Studies ISSN 2162-3058 2021, Vol. 11, No. 2

Giuliano, L., Levine, D., \& Leonard, J. (2006). Do Race, Age, and Gender Differences Affect Manager-Employee Relations? An Analysis of Quits, Dismissals, and Promotions at a Large Retail Firm." UC Berkeley: Institute for Research on Labor and Employment. http://escholarship.org/uc/item/9tc8n5j7

Hein, C., \& Cassirer, N. (2010). Workplace solutions for child-care. Geneva, Switzerland: International Labour Office.

Hill, E. J., Jacob, J. I., Shannon, L. L., Brennan, R. T., Blanchard, V. L., \& Martinengo, G. (2008). Exploring the relationship of workplace flexibility, gender, and life stage to family-to-work conflict, and stress and burnout. Community, Work \& Family, 11(2), 165-181. https://doi.org/10.1080/13668800802027564

HR Asia (2018, May 11). 75\% of Malaysian Mothers Quit Their Jobs Due to a Lack of Flexibility.

https://hrasiamedia.com/uncategorized/2018/75-of-malaysian-mothers-quit-their-jobs-due-toa-lack-of-flexibility/

Hundera, M. B. (2014). Factors affecting academic staff turnover intentions and the moderating effect of gender. International Journal of Research in Business Management, 2(9), 2321-2886.

Islam, M. A., \& Jantan, A. H. (2017). The Glass ceiling: Career Barriers for Female Employees in the Ready-Made Garments (Rmg) Industry of Bangladesh. Academy of Strategic Management Journal, 16(3), 1-11.

Ismail, M., \& Ibrahim, M. (2008). Barriers to career progression faced by women: Evidence from a Malaysian multinational oil company. Gender in Management: An International Journal, 23(1), 51-66. https://doi.org/10.1108/17542410810849123

Jabeen, F., Friesen, H. L., \& Ghoudi, K. (2018). Quality of work life of Emirati women and its influence on job satisfaction and turnover intention: evidence from the UAE. Journal of Organizational Change Management, 31(2), 352-370,

Kelly, R. M., \& Marin, A. J. D. (1998). Position power and women's career advancement. Women in Management Review, 13(2), 53-66.

King, E. B. (2008). The effect of bias on the advancement of working mothers: Disentangling legitimate concerns from inaccurate stereotypes as predictors of advancement in academe. Human Relations, 61(12), 1677-1711. https://doi.org/10.1177/0018726708098082

Kivimäki, M., Jokela, M., Nyberg, S. T., Singh-Manoux, A., Fransson, E. I., Alfredsson, L., ... \& Clays, E. (2015). Long working hours and risk of coronary heart disease and stroke: a systematic review and meta-analysis of published and unpublished data for 603838 $\begin{array}{llll}\text { individuals. } & \text { The } & \text { Lancet, } & \text { 386(10005), }\end{array}$ https://doi.org/10.1016/S0140-6736(15)60295-1

Koch, T. (1994). Establishing rigour in qualitative research: The decision trail. Journal of Advanced Nursing, 19(5), 976-986. https://doi.org/10.1111/j.1365-2648.1994.tb01177.x 
Kuruppuarachchi, K. A. P. S. T., \& Surangi, H. A. K. N. S. (2020). The Glass Ceiling and Women Career Advancement: A Study Based on Ready - Made Garment Industry in Sri Lanka. Kelaniya Journal of Management, 8(2), 18-39. https://doi.org/10.4038/kjm.v8i2.7581

Kremer, I. (2016). The relationship between school-work-family-conflict, subjective stress, and burnout. Journal of Managerial Psychology, 31(4), 805-819. https://doi.org/10.1108/JMP-01-2015-0014

Leonard, J. S., \& Levine, D. I. (2006). The effect of diversity on turnover: A large case study. ILR Review, 59(4), 547-572. https://doi.org/10.1177/001979390605900402

Leskinen, E. A., Rabelo, V. C., \& Cortina, L. M. (2015). Gender stereotyping and harassment: A “catch-22" for women in the workplace. Psychology, Public Policy, and Law, 21(2), 192.

Lincoln, S. Y., \& Guba, E. G. (1985). Naturalistic inquiry. Thousand Oaks, CA: Sage. https://doi.org/10.1016/0147-1767(85)90062-8

Losoncz, I., \& Bortolotto, N., 2009. Work-life balance: The experiences of Australian working mothers. Journal of Family Studies, 15(2), 122-138. https://doi.org/10.5172/jfs.15.2.122

Marcinkus, W. C., \& Hamilton, E. A. (2006, August). Women at a crossroads: identity, influence, and choices regarding work. In Academy of Management Proceedings (Vol. 2006, No. 1, pp. G1-G6). Briarcliff Manor, NY 10510: Academy of Management. https://doi.org/10.5465/ambpp.2006.22898281

McKinsey (2020, September 30). Women in the Workplace 2020. https://doi.org/10.1144/geosci-30-8

Merriam, S. B., \& Tisdell, E. J. (2016). Qualitative research: A guide to design and implementation, 4th ed. San Francisco: Jossey Bass.

Ministry of Education (2018). Quick Facts 2018. Malaysia Educational Statistics. https://www.moe.gov.my/penerbitan/1587-quick-facts-2018-malaysia-educational-statistics-1 /file

Moilanen, S., May, V., Räikkönen, E., Sevón, E., \& Laakso, M.-L. (2016). Mothers' non-standard working and childcare-related challenges: A comparison between lone and coupled mothers. International Journal of Sociology and Social Policy, 36(1/2), 36-52. https://doi.org/10.1108/IJSSP-11-2014-0094

Morley, L., Berma, M., \& Hamid, B. D. H. A. (2017). Managing modern Malaysia: women in higher education leadership. In the Changing Role of Women in Higher Education (pp. 137-154). Springer, Cham.

Nemoto, K. (2013). Long working hours and the corporate gender divide in Japan. Gender, work \& organisation, 20(5), 512-527. https://doi.org/10.1111/j.1468-0432.2012.00599.x

Nie, D., Lämsä, A. M., \& Pučètaitè, R. (2018). Effects of responsible human resource management practices on female employees' turnover intentions. Business Ethics: A 
European Review, 27(1), 29-41.

Polit, D. F., \& Beck, C. T. (2012). Nursing research: Principles and methods. Philadelphia, PA: Lippincott Williams \& Wilkins.

Raley, K. (2019). The Economic Impact of Gender Diversity On Boards | AZ Big Media. $<$ https://azbigmedia.com/business/business-leaders/women-business/the-economic-impact-of -gender-diversity-on-boards

Ramasamy, C. (2019, January 28). It is a scandal that working mothers are $40 \%$ more stressed than other people. The Guardian. https://www.theguardian.com/lifeandstyle/2019/jan/28/scandal-working-mothers-40-per-centmore-stressed-other-people

Raišienė, A. G., Rapuano, V., Varkulevičiūtè, K., \& Stachová, K. (2020). Working from Home-Who is Happy? A Survey of Lithuania's employees during the COVID-19 quarantine period. Sustainability, 12(13), 5332. https://doi.org/10.3390/su12135332

Rendon, R. A. (2016). Work-Life Balance Among Working Married Women: What Social Workers Need to Know. Unpublished dissertation. California State University, San Bernardino

Rakin, E. (2018). 75\% Of New Working Mothers in Malaysia Quit Their Jobs. <https://www.businessinsider.my/75-mothers-malaysia-jobs-monster-survey>

Ridgeway, Cecelia L., and Paula England. 2007. Sociological approaches to sex discrimination in employment. In Sex discrimination in the workplace, edited by Faye J. Crosby, Margaret S. Stockdale, and S. Ann Ropp. Maiden, MA: Blackwell Publishing

Ritchie, H., \& Roser, M. (2019). Gender Ratio. [online] Our World in Data. $<$ https://ourworldindata.org/gender-ratio>

Sandberg, S. (2015). Lean in-women, work and the will to lead. NHRD Network Journal, 8(2), 137-139. https://doi.org/10.1177/0974173920150225

Shields, M. (1999). Long working hours and health. Health Rep, 11(2), 33-48.

Saunders, M., Lewis, P., \& Thornbill, A. (2016). Research methods for business students, Pearson, Essex.

Schueller-Weidekamm, C., \& Kautzky-Willer, A. (2012). Challenges of Work-Life Balance for Women Physicians/Mothers Working in Leadership Positions. Gender Medicine, 9(4), 244-250.

Sharma, S., \& Sharma, M. (2012). Gender equality in the workplace: the perceptive reality. Social Sciences Directory, 1(1), 19-33. https://doi.org/10.7563/SSD_01_01_03

Stoeber, J., \& Rennert, D. (2008). Perfectionism in schoolteachers: Relations with stress appraisals, coping styles, and burnout. Anxiety, Stress, \& Coping, 21(1), 37-53.

Sudha, J., \& Karthikeyan, D. P. (2014). Work Life Balance of Women Employee: A Literature 
Review. International Journal of Management Research and Review, 4(8), 797-804.

Sundaresan, S. (2014). Work-life balance-implications for working women. OIDA International Journal of Sustainable Development, 7(7), 93-102.

Sultana, A. M., \& Zulkefli, N. E. B. M. (2012). Discrimination against women in the developing countries: a comparative study. International Journal of Social Science and Humanity, 2(3), 256.

Tajlili, M. H. (2014). A framework for promoting women's career intentionality and work-life integration. The Career Development Quarterly, 62(3), 254-267. https://doi.org/10.1002/j.2161-0045.2014.00083.x

Talent Corp. (2013). Retaining Women in The Workplace. Flexworklife.my. $<$ http://flexworklife.my/wp-content/uploads/2013/07/ACC5-Retaining-Women-in-the-Workf orce.pdf $>$

Tlaiss, H., \& Kauser, S. (2010). Perceived organisational barriers to women's career advancement in Lebanon. Gender in Management: An International Journal, 25(6), 462-496. https://doi.org/10.1108/17542411011069882

Turban, S., Wu, D., \& Zhang, L. (2019). Research: When Gender Diversity Makes Firms More Productive. [online] Harvard Business <https://hbr.org/2019/02/research-when-gender-diversity-makes-firms-more-productive>

Worrall, L., Harris, K., Stewart, R., Thomas, A., \& McDermott, P. (2010). Barriers to women in the UK construction industry. Engineering, Construction and Architectural Management. 17(3), 268-281

Williams, J. C., Phillips, K. W., \& Hall, E. V. (2016). Tools for change: Boosting the retention of women in the stem pipeline. Journal of Research in Gender Studies, 6(1), 11-75.

Womens Aid Organization (2016, August 9). Discrimination Towards Women Remains

Prevalant in the Malaysian Workplace. https://wao.org.my/discrimination-towards-women-remains-prevalant-in-the-malaysian-work place/

Wu, R., \& Cheng, X. (2016). Gender equality in the workplace: the effect of gender equality on productivity growth among the Chilean manufacturers. The Journal of Developing Areas, 50(1), 257-274.

Yapp, R. (2018). Working Women still do housework. Daily Mail http://www.dailymail.co.uk/news/article-206381/Working-women-housework.html 


\section{Copyright Disclaimer}

Copyright for this article is retained by the author(s), with first publication rights granted to the journal.

This is an open-access article distributed under the terms and conditions of the Creative Commons Attribution license (http://creativecommons.org/licenses/by/4.0/). 